\title{
Emotional Design in Multimedia Learning: Effects of Multidimensional Concept Maps and Animation on Affect and Learning
}

\author{
Li-Chu Tien ${ }^{1}$, Chei-Chang Chiou ${ }^{2 \star}$, Yueh-Shian Lee ${ }^{3}$ \\ ${ }^{1}$ Department of Tourism and Recreation management, Overseas Chinese University, Taichung 40721, Taiwan, R.O.C. \\ 2 Department of Accounting, National Changhua University of Education, Changhua 500, Taiwan, R.O.C. \\ ${ }^{3}$ Department of Business Administration, MINGDAO University, Pitou, Changhua 52345, Taiwan, R.O.C.
}

Received 18 January 2018 • Revised 27 May 2018 • Accepted 25 June 2018

\begin{abstract}
This study examines the benefits of multimedia materials that combine animation and multidimensional concept maps. In this quasi-experimental study, 114 students from two classes at the college of business of a private university in Taiwan participated in a 6-week teaching experiment. The research instruments included learning achievement tests and a learning well-being scale. The data analyses used a one-way analysis of covariance, a paired sample t-test, a Sobel's z-test, and a path regression analysis. The results indicated that students who learned with multimedia materials that combined animation and colourful multidimensional concept maps presented significantly higher learning well-being than students who learned with achromatic multidimensional concept maps. Moreover, students who learned with multimedia materials that combined animation and colourful multidimensional concept maps presented significantly higher learning achievement than students who learned with achromatic multidimensional concept maps. A mediation analysis suggested that learning wellbeing mediated the effect of learning with different multimedia materials on students learning achievement. This study suggests that multidimensional concept maps and animation have a function in multimedia instruction.
\end{abstract}

Keywords: emotion, learning achievement, learning well-being, multidimensional concept maps, multimedia animation

\section{INTRODUCTION}

Computer-based multimedia learning materials are designed to facilitate learning. Research has shown that multimedia learning benefits cognitive learning (Mayer, 2009; Mayer, \& Moreno, 2003; Park, Plass, \& Brunken, 2014; Um, Plass, Hayward, \& Homer, 2012). In recent years, research on multimedia learning has begun to consider the influences of affective processes, such as motivation (Mayer, 2014; Park, Moreno, Seufert, \& Brunken, 2011) and emotion (Heidig, Muller, \& Reichelt, 2015; Park, Knorzer, Plass, \& Brunken, 2015; Plass et al., 2014; Um et al., 2012). Investigating how the design of multimedia learning materials can foster positive emotions (e.g. well-being) is important because emotions that learners experience in their academic settings are related to their motivation, satisfaction and academic achievement (Pekrun, Goetz,Titz, \& Perry, 2002; Plass et al., 2014; Um et al., 2012).

Heidig et al. (2015) argued that emotional design in multimedia learning involves the use of visual design elements that can prompt positive emotions and therefore facilitate learning. An emotional design in multimedia learning materials can include additional elements or different intrinsic design elements. Additional elements were shown to positively affect learners' emotions and motivation and therefore benefit learning (Heidig et al. 2015; Park et al., 2011). For changing intrinsic design elements, Um et al. (2012) and Plass et al. (2014) demonstrated that the joint contribution of warm colours and round shapes as emotional design elements can evoke in learners positive emotions, which in turn facilitate affective and cognitive outcomes.

(C) 2018 by the authors; licensee Modestum Ltd., UK. This article is an open access article distributed under the terms and conditions of the Creative Commons Attribution License (http://creativecommons.org/licenses/by/4.0/). \m9316621@yahoo.com.tw $\square$ ccchiou@cc.ncue.edu.tw (*Correspondence) $\square$ leeyuehshian@hotmail.com 


\section{Contribution of this paper to the literature}

- This article introduces the multimedia design idea of integrating colourful multidimensional concept maps with animation into multimedia learning research, and opens up a new research direction for multimedia learning literature.

- This article explores the impact of integrated colourful multidimensional concept maps and animation multimedia design on students' affection and cognition.

- The results of this article show that using multimedia materials integrating colourful multidimensional concept maps and animation can positively improve students' learning well-being, and can further positively influence their learning achievement through improving their learning well-being.

Based on the above review, we are only beginning to understand the role emotions may play in multimedia learning. The potential of an emotional design in multimedia learning needs to further be explored (Heidig et al. 2015). In line with the positive advantage of additional elements and intrinsic design elements in emotional design, this paper introduces multidimensional concept maps as new intrinsic design elements and daily-life animation as an additional new element of multimedia learning. A multidimensional concept map is a visual representation which can connect new learning materials with prior knowledge (Chiou, Tien, \& Lee, 2015; Mayer, 2005), and it can positively impact motivation, satisfaction, and learning outcomes for learners (Chiou et al., 2015). Based on the suggestion of Um et al. (2012) and Plass et al. (2014) that the intrinsic visual design elements of colour and shape can induce learner's emotions, a multidimensional concept map for its advantage for learning may have a potential to be as a new intrinsic visual design element of an emotional design in multimedia learning materials. Additionally, daily-life animation (such as daily-life familiar sound and dynamic materials) is an auditory and (or) visual material which can attract the attention of learners and improve their interest in learning and satisfaction (Chiou et al., 2015). Hence daily-life animation may be a good additional element of an emotional design in multimedia learning materials. According to Paivio (1986), Dual Coding Theory (DCT) posits two distinct information processing systems: auditory and visual. When presenting a learning material, using these two systems simultaneously is better than only one (Paivio, 1971; see Chiou et al., 2015 for more detail). Based on the DCT, Chiou et al. (2015) combined multidimensional concept maps with animation and proved their benefits to improving learners' satisfaction and learning achievement (the rationale for combining these two elements see Chiou et al. (2015) for more detail).

Therefore, this paper further investigates the effects of multidimensional concept maps combined with animation in multimedia materials on learning well-being and learning achievement.

\section{MULTIMEDIA LEARNING, POSITIVE EMOTIONS, LEARNING WELL-BEING AND LEARNING PERFORMANCE}

In the context of learning, researchers have been interested in positive emotions directly related to instruction, learning, and achievement (Pekrun et al., 2002; Plass et al., 2014; Um et al., 2012). Studies of cognitive processing have found that positive emotions can enhance learners' motivation and stimulate learning; thus, they can enhance learning performance (Gerjets \& Scheiter, 2003; Pass \& Van Merrienboe, 1994; Pekrun, 2006). Brookover et al. (1979) adopted the 'mediating model' from the viewpoint of sociology and believed that students could improve learning outcomes through learning with pleasant emotions. Efklides, Kourkoulou, Mitsiou, and Ziliaskopoulou (2006) found that more positive emotions among learners resulted in a higher readiness to invest mental effort in a learning task. Isen, Shalker, Clark, and Karp (1978) and Isen, Daubman, and Nowicki (1987) showed that positive emotions enhance recall and serve as retrieval cues of long-term memory. Academic positive emotions can be equated with learning well-being and contribute to learning well-being (Fredrickson, 1998; Lyubomirksy, King, \& Diener, 2005). Learning well-being is the subjective feeling for learning, including enjoyment, satisfaction, and the achievement of an objective, which comes from the process of learning with materials. Ausubel (1963) believed that effective learning leads to a positive emotional development, thereby enhancing learning well-being. The findings from these studies suggest that academic positive emotions can improve learning well-being and enhance cognitive achievement.

Past research has argued that good multimedia learning environments can motivate learners and thus improve their cognitive outcomes (Mayer, 2009; Mayer, \& Moreno, 2003). Moreno (2006) proposed the Cognitive-Affective Theory of Learning with Media (CATLM), which expands Mayer's (2005) Cognitive Theory of Multimedia Learning (CTML) and may provide guidance by adding motivational and emotional factors to CTML as mediating effects on the cognitive engagement of learners. Heidig et al. (2015) asked, 'How can we design multimedia learning materials that are appealing while still being effective for learning?' That is, how can we design multimedia learning materials that lead to positive emotions or learning well-being and still enhance learning outcomes? Therefore, we 
are interested in determining whether adding multidimensional concept maps and animation as specific verbal and visual design elements in multimedia learning environments can impact learners' learning well-being and thus foster learning.

\section{Concept Map, Animation, and Multimedia Learning}

Multimedia animation can contain words, pictures, sounds, images, and moving pictures (Chiou et al., 2015). Multimedia learning is defined as learning from these design features of multimedia animation materials. Previous studies have shown that multimedia animation increases learners' interest and motivation and improves information processing and learning achievement (Chiou et al., 2015; Holzinger, Kickmeier-Rust, \& Albert, 2008; Schar \& Zimmermann, 2007; Tien, Chiou, \& Liao, 2018). The theory of these studies is based on Mayer's (2005) CTML, focused on cognitive processes. Mayer's CTML describes, based on the dual channel assumption of Dual Coding Theory (DCT) (Paivio, 1986), how multimedia information is processed in separate channels (auditory/verbal and visual/pictorial) for verbal (words and narration or sounds) and visual (images and animation) information (Mayer, 2001). Paivio's (1986) DCT postulates that humans receive cognitive information through two channels: auditory and visual. DCT proposes that verbal and visual information are processed differently and along distinct channels in the human mind, creating separate representations for information processed in each channel (Bieniek, 2008). Deimann and Keller (2006) argued that using a single channel to process information makes information compete with other information in a limited capacity of working memory, thereby causing cognitive overload. McPherson (2000) and Bieniek (2008) argued that memory for some verbal information improves if a relevant visual is also presented or if the learner can imagine a visual image to go with the verbal information. Likewise, visual information can often be enhanced when coupled with relevant verbal information, whether real or imagined (Anderson \& Bower, 1973; Bieniek, 2008; Sadoski, 2005). Holzinger et al. (2008) indicated that teaching material representations that incorporate verbal (words and sounds) and visual (images and animation) information are better than visual (text and pictures) materials alone because they simultaneously stimulate two sensory channels (Chiou et al., 2015; Tien et al., 2018).

Paivio's (1986) DCT has been applied to the use of multimedia representations. According to Paivio, there are two ways a person can expand on learned multimedia materials: verbal associations and visual imagery. Mayer $(2001,2005)$ argued that verbal and visual materials can improve learning performance, and he proposed CTML by integrating Information Processing Theory (IPT) (Keefe \& Jenkins, 1997), DCT (Paivio, 1986), and a model of working memory (Baddeley, 1992). Mayer's (2005) selection-organization- integration (SOI) cognitive model of multimedia learning indicates that learning is a process of selecting relevant verbal and visual materials, organizing verbal and visual mental representations in coherent structures in working memory, and integrating verbal and visual mental representations with one another and with prior knowledge (Um et al., 2012). Therefore, the SOI model emphasizes that a good multimedia material design involves incorporating verbal and visual information, considering the limited capacity of working memory, and integrating new information with prior knowledge.

According to the multimedia material design principle that incorporates verbal associations and visual imagery (Mayer, 2005), this research proposes combining multidimensional concept maps and animation into the design of multimedia materials. Multimedia animation is a representation of visual imagery. Although animation can improve learners' interest and motivation, it may impose extraneous cognitive load, which, in turn, harms learning (Um et al., 2012). Extraneous cognitive load, based on Cognitive Load Theory (Sweller, 1988), describes processing demands of information that is not directly related to the learning task and is a result of the instructional design of the materials (e.g., unnecessary animation) (Kalyuga, 2012; Um et al., 2012). Animation such as charts, video, images, and pictures, similarly to seductive details, may be appealing and interesting but unnecessary for learning, and it is usually assumed that they add demand for the processing of non-essential information and therefore hurt learning (Park, Flowerday, \& Brunken, 2015; Plass et al., 2014). The introduction of appealing additional design elements, such as animation, may induce positive emotions in learners and facilitate their interest and intrinsic motivation, thus fostering learning (Plass et al., 2014; Um et al., 2012). Therefore, the benefit of additional elements (e.g., animation) for learning depends on whether their effectiveness in increasing learners' interest and motivation is enough to compensate for the added processing demands.

To retain positive emotions and reduce the extraneous cognitive load that animation representations produce, we use multidimensional concept maps and daily-life images and sounds. A concept map is a hierarchically arranged, graphic representation of the associations among concepts (Chiou, 2009; Novak, 1990). A concept map representation is an outstanding tool to promote meaningful learning (Novak, 1990). Meaningful learning involves cognitive processing, including building connections between visual and verbal representations (Mayer \& Moreno, 2003) and integrating new information with existing knowledge (Novak, 1990), which is the goal of multimedia learning (Mayer \& Moreno, 2003). A multidimensional concept map arranges complex or difficult concepts into multiple dimensions to simplify the representation of concepts (Huang et al., 2012). Concept maps can be representations of verbal associations. According to DCT, verbal associations belong to associative processing and 
are where different logogens are linked to create a deeper understanding of the original input (Paivio, 1986; Paivio \& Sadoski, 2011). Relying on referential processing (i.e., referential connection) (Paivio, 1986), animation imagery and multidimensional concept map associations can be activated together for more complete comprehension and memory.

\section{Multidimensional Concept Maps, Daily-life Animation, Positive Emotions, and Extraneous Cognitive Load}

The simplest semantic basis of concept maps is two concepts connected by a linking word to form a proposition (Novak \& Gowin, 1984). Propositions are two or more concept labels linked by words in a semantic unit (Chiou, 2008). Concept maps can be used as a knowledge representation tool to reflect the relationships between concepts that reside within an individual's long-term memory (Chiou, 2008; Jacobs-Lawson \& Hershey, 2002). According to DCT, the associating characteristics of concept maps are the same as logogens that are linked, and associative processing can create an understanding of linguistic meaning (Paivio \& Sadoski, 2011). Concept maps also conform to Mayer's (2005) good multimedia material design principle, which emphasizes the integration of receiving information with prior knowledge. A concept map is also a visual representation because of its graphic property (Chiou et al., 2015). Therefore, concept map representations are better at reducing cognitive load than traditional linear sentence representations because of their merits of integrating verbal and visual mental representations with one another and with prior knowledge (Chiou et al., 2015; Mayer, 2005; Tien et al., 2018). However, Huang et al. (2012) recommended multidimensional concept maps because information structured with Novak's traditional two-dimensional concept maps has been reported to have difficulty explaining the knowledge of multiple concepts simultaneously and thus might lead to cognitive overload (Beyerbach, 1998; Huang et al., 2012; Tien et al., 2018).

The theoretical basis of multidimensional concept maps is Miller's (1956) theory on the limited capacity of humans' short-term memory. Following Miller's (1956) principle, a multidimensional concept map divides the content of learning units into a small number of fragments and makes each multimedia screen not over $7 \pm 2$ concepts (e.g., Figures 2-4). This method also conforms to the segmenting principle proposed by Mayer and Moreno (2003), which suggests that presentation is broken down into bite-size segments. Therefore, the multidimensional concept maps have the potential to help learners understand difficult, multiple concepts and reduce their cognitive overload (Huang et al., 2012). The advantages of multidimensional concept maps may offset the higher cognitive load from positive emotions due to introducing seductive details, such as animation, into a multimedia environment.

Based on Moreno's (2006) CATLM, Um et al. (2012), Plass et al. (2014) and Park et al. (2015) investigated the influence of seductive details that induced positive emotions on learning. They found that seductive details, such as additional text, animated pictures, face-like round shapes and warm colours, induced positive emotions. Additionally, the effect on learning of positive emotions depended on the extraneous cognitive load induced by seductive details and the motivation improved by seductive details. Regarding the effectiveness of seductive details for learning performance, Park et al. (2015) indicated when the seductive details conveyed learning goal-relevant information, they did not interfere with learning and led to focused attention and affective reaction, which fostered a high-quality learning process. In the present study, the animation we designed considered daily-life images and sounds (or music) that were related to the learning content. For example, daily-life advertisement music for 7-11 and images 10 and animation features, which all were related to the learning content of related to the merchandising industry, were used to engage the attention of learners and to induce positive emotions but not to increase the extraneous cognitive load (Park et al., 2015). According to Park et al. (2015), the animation we designed should have a low cognitive load.

To resolve the cognitive load problem and enhance the effectiveness of positive emotions, we designed multimedia materials with multidimensional concept maps and animation. We were interested in how multimedia materials impacted learning well-being and learning achievement. Specifically, this paper explored the following questions:

1. Can students who learn with multimedia materials with colourful multidimensional concept maps and animation (CMCMAMs) improve learning achievement?

2. Can students who learn with CMCMAMs increase learning well-being?

3. Does learning well-being mediate the effect of learning with CMCMAMs on students' learning achievement? 


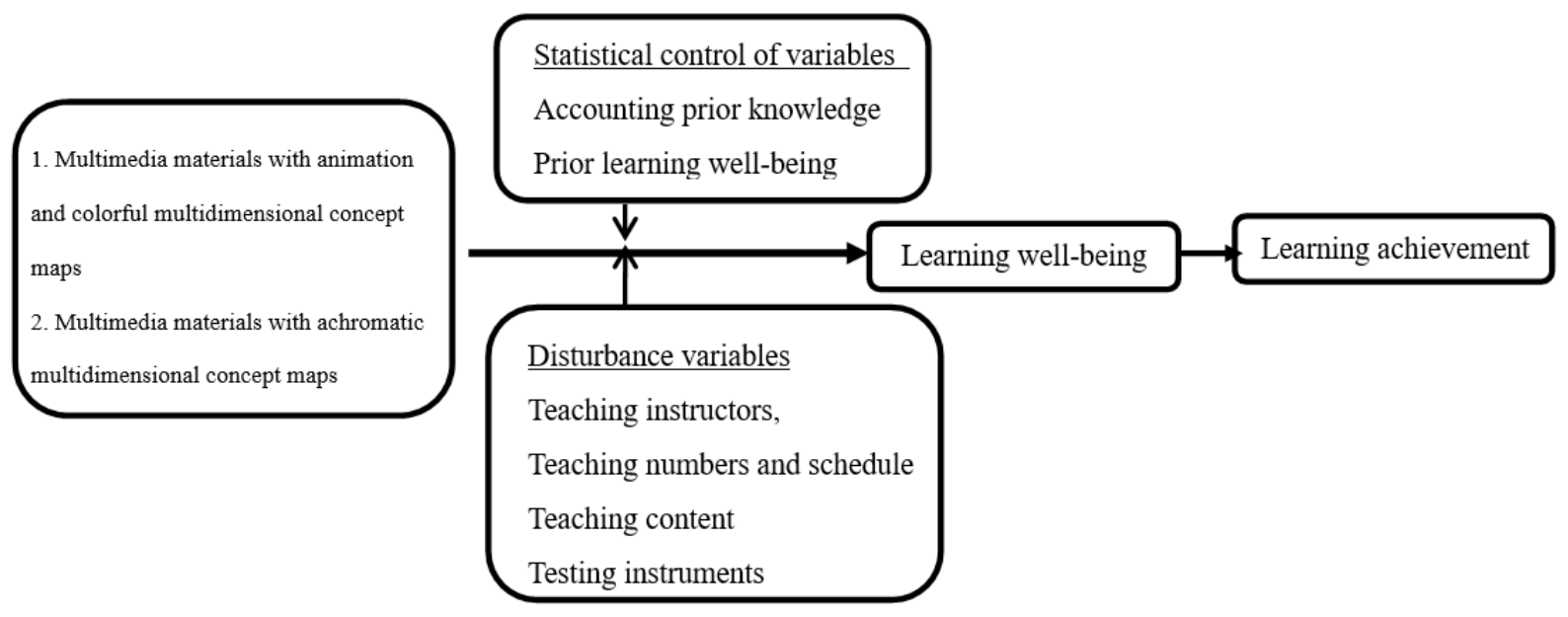

Figure 1. Research framework

\section{METHOD}

\section{Participants, Experimental Design and Data Analysis}

This study adopted a quasi-experimental design with two participant groups. Participants were 114 students from two classes in the college of business at a private university in Taiwan. Using an unequal control group quasiexperimental design, 56 students were assigned to the experimental group and 58 students to the control group. Students in the experimental group learned with CMCMAMs, while students in the control group learned with multimedia materials with achromatic multidimensional concept maps (AMCMMs). The dependent variable was learning achievement, and the mediation variable was learning well-being. The research framework is shown in Figure 1.

This research used a financial accounting course as the experimental course because the most important job in learning financial accounting was to clarify and integrate accounting concepts (Chiou, 2008; Chiou et al., 2015). Therefore, the concept map material was very suitable for financial accounting courses. In addition, the financial accounting course was an accounting training course for practical business applications. Animation related to daily life also had a positive effect on learning this course (Chiou et al., 2015; Mayer \& Moreno, 2002). Therefore, this study used the financial accounting course as the experimental course.

The data analyses in this research used a one-way analysis of covariance (ANCOVA), a paired sample t-test, a Sobel's z-test, and a path regression analysis. The control group had 58 students $(50.9 \%)$, and the experimental group had 56 students (49.1\%). There were 64 female participants (34 in the control group and 30 in the experimental group) and 50 male participants (24 in the control group and 26 in the experimental group).

\section{Research Instruments}

\section{Learning achievement tests}

The learning achievement pre-test included journaling, posting, trial balance, and adjusting. The learning achievement post-test included merchandising and inventory. The learning achievement pre-test and post-test were evaluated with two-way specification table analyses to obtain the content validities based on accounting teaching objectives. Fifty-seven students at the college of business at a private university were then asked to implement a preliminary examination of the learning achievement pre-test and post-test. Based on the standards of degree of difficulty (from 0.4 to 0.8), the degree of discrimination (greater than 0.25) (Ebel \& Frisbie, 1991) and KR-20 internal consistency reliability ( 0.82 and 0.85$), 5$ questions were removed and 20 questions were reserved as formal test questions for the pre-test and post-test.

\section{Learning well-being scale}

Lu and Lin's (2003) Chinese Learning Well-being Scale, an instrument with nine items assessed on a four-point Likert scale, was used to measure students' learning well-being before and after the learning phase of the formal experiment. Before the formal experiment, the teacher taught students with traditional linear teaching materials on 
journaling, posting, trial balance, and adjusting. Then, the Learning Well-being Scale was used to measure students' learning well-being before the learning phase of the formal experiment. After the learning phase of the formal experiment, the same learning well-being scale was again used to measure students' learning well-being. Sample items are "I am satisfied with the design and the whole representation of this material" and "I am happy when I use this material to learn". The possible total score ranged from 0 to 36, with higher scores reflecting higher learning well-being, and vice versa. The preliminary examination of this scale showed that the correlation coefficients of individual questions and the total scale were .51 to $.83, p<.01$, indicating high content validity (Kerlinger, 1986). A factor analysis was used to determine the construct validity, and the explained variance was $49.22 \%$. Cronbach's a coefficient was .85 , with good reliability.

\section{Experimental Materials Design}

The experimental materials design mainly referred to Accounting IFRS (Keiso, 2012) for content and referred to Mayer's (2005) CTML and Huang et al.'s (2012) multidimensional concept maps for multimedia. The validity of the materials was determined through an expert review by two accounting teachers, two multimedia and digital teaching materials experts, and two course experts.

\section{CMCMAMs design}

CMCMAMs were designed by integrating IPT (Keefe \& Jenkins, 1997), DCT (Paivio, 1996), the Generative Theory of Multimedia Learning (Mayer, 1997) and colour theory (Pett \& Wilson, 1996) and by referring to Huang et al.'s (2012) design principles.

Applying IPT to design CMCMAMs. Miller (1956) found that the capacity of humans' short-term memory is $7 \pm 2$ units. Based on the limited capacity of short-term memory, this study used Mayer's $(1997,2001,2005)$ multimedia design principles to design accounting multimedia materials, dividing the content of learning units into a small number of fragments and limiting each multimedia screen to $7 \pm 2$ concepts. For example, Figures 2 (including five concepts on the screen), 3, and 4 abide by Miller's (1956) rule that each screen does not exceed $7 \pm 2$ concepts. Additionally, images and sounds (or music) in the materials that link students' past or present daily-life experiences (e.g., 1 S ) can enhance the long-term recall of learned materials (Holzinger et al., 1998). Coloured teaching materials can improve students' learning motivation and facilitate learning (Lamberski, 1980; Pett \& Wilson, 1996). Chiou, Lee, and Liu (2012) showed that hierarchical colourful concept maps in teaching materials can enhance students' learning achievement. Plass et al. (2014) indicated that warm colours can induce positive emotions in learners and in turn facilitate comprehension. Colour theory (see Chiou et al., 2012) thus was used to construct learning hierarchies for concept maps, which can be distinguished into (1) basic learning units, (2) advanced learning units, and (3) practice units. For instance, in Figure 2, the first hierarchy is the basic learning unit "purchases", which is displayed with a deep warm colour. The second hierarchy is the advanced learning units "periodic inventory system" and "perpetual inventory system", which are shown with a warm colour. The third hierarchy is the advanced learning and practice units "purchases" and "inventory", which are shown with a light warm colour. Students first learned the basic accounting concepts and then learned the advanced accounting concepts. In addition to colour theory to facilitate learning, the materials included a hyperlink function. The hyperlink function benefit concepts contained in each web page did not exceed learners' short memory capacity (Miller, 1956) and helped learners gradually deepen and broaden their knowledge by following the hyperlinks in the graph (see section "Using hyperlinks in CMCMAMs to promote deepen and broad learning" and Huang et al., 2012). When a student has learned and fully understood the basic units in Figure 2, she/he can follow the hyperlinks that lead to the advanced units for deeper and broader learning, as in Figure 3. 


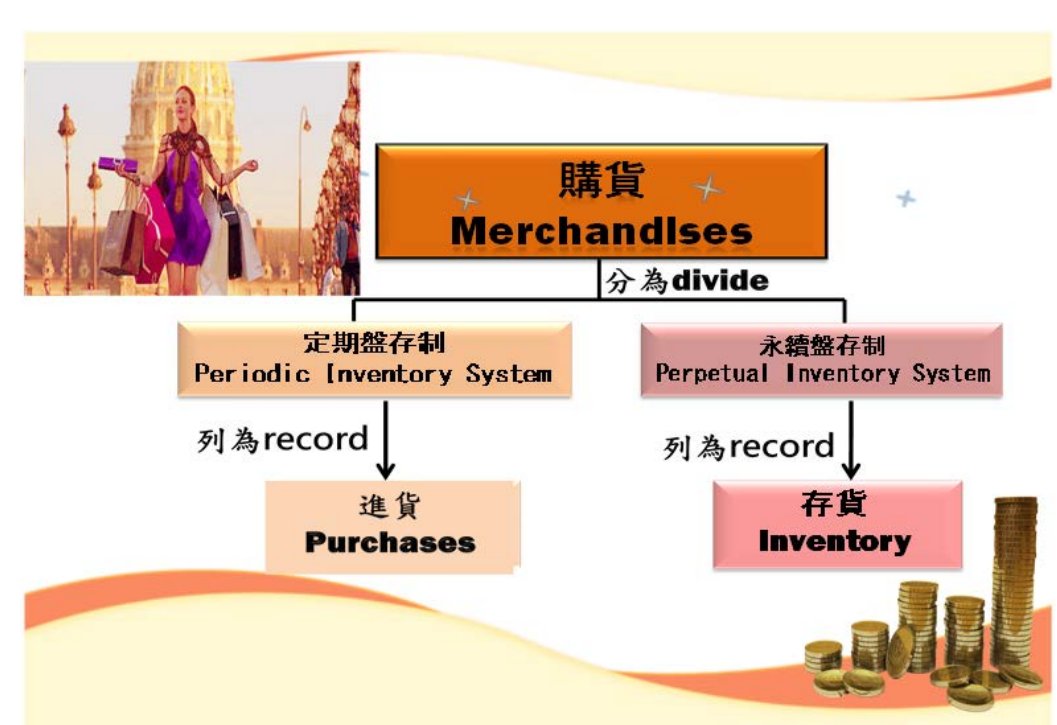

Figure 2. CMCMAMs - the basic unit

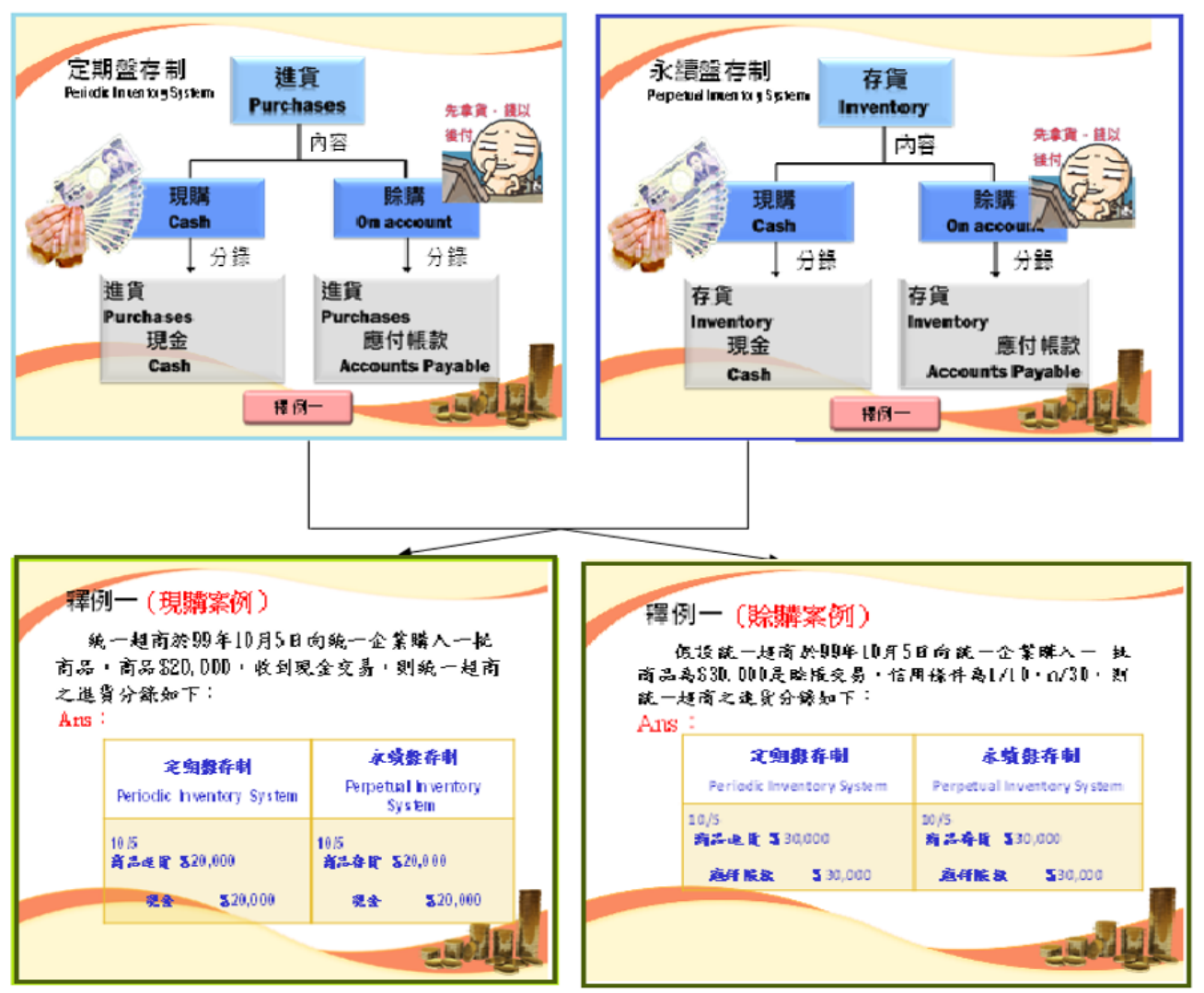

Figure 3. CMCMAMs - the advanced units 


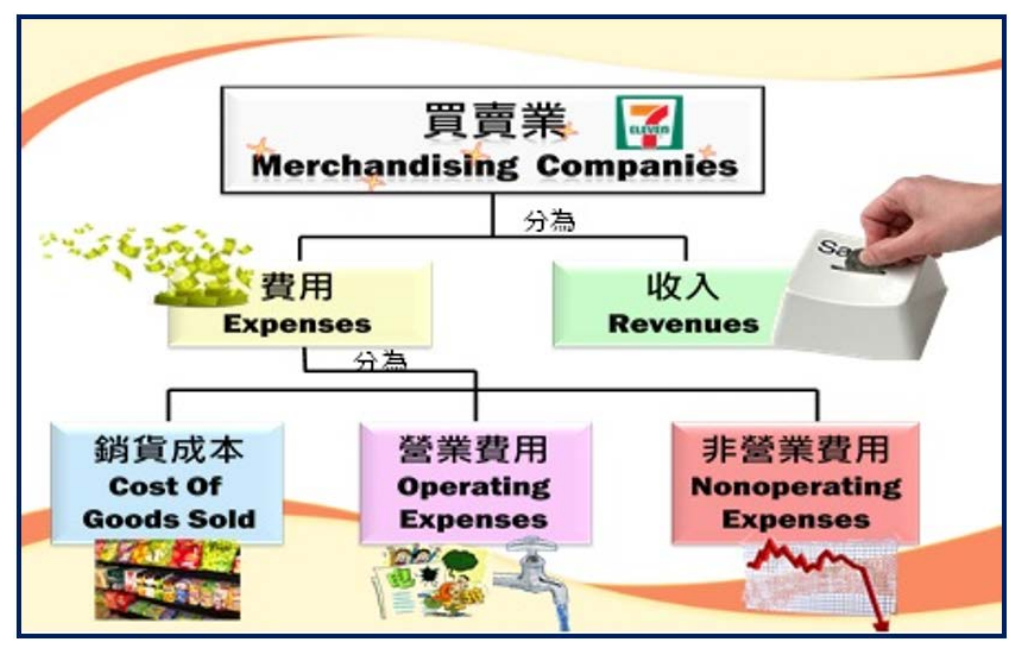

Figure 4. CMCMAMs

The daily-life images described above were designed based on the principle of information with which the students were familiar, which can make the abstractive cognitive structure concrete and visualizable and thus enhance knowledge (Biehler \& Snowman, 1990; Woolfolk, 2007). In Figure 2, the basic unit "purchases" was designed using department store anniversary music and images of buying goods. Students could extract their memories about buying goods through their past daily-life experiences related to purchasing images and sounds. Daily-life animation, which is related to learning tasks, can induce students' positive emotions (Park et al., 2015; Um et al., 2012) and engage and focus students' attention (Park et al., 2015), thus allowing students to concentrate on their lessons. Chiou (2009) argued that if any knowledge or teaching can connect students' prior knowledge, new knowledge can easily be memorized. Therefore, effective learning should be based on students' prior knowledge and experience to shape their knowledge structure system (Chiou, 2009).

Based on DCT, as shown in Figure 4, the CMCMAMs used the daily-life 7-11 advertising voice (auditory), "Merchandising Companies" (text) and (image and animation) to stimulate students' visual and auditory senses, to attract students' attention, and then to make students immediately accept the information into their sensory system. A daily-life example such as 7-11 convenience stores was used to describe the meaning of the merchandising industry. When students saw the 7-11 their (verbal and non-verbal) mental models for the merchandising industry were converted and integrated into their long-term memory (Mayer, 2005; Moreno, 2006). According to the theories of Mayer (2005) and Moreno (2006), active consciousness for instructional media (i.e., CMCMAMs) enters working memory through visual and auditory senses and then forms a non-verbal (pictorial) mental model, a verbal mental model, and a connection between the two models. The two mental models are then integrated systematically and stored in the long-term memory.

Using hyperlinks in CMCMAMs to promote deepen and broad learning. Based on the limited capacity theory of short-term memory (Baddeley, 1992; Miller, 1956) and the segmenting principle (Mayer \& Moreno, 2003), Huang et al. (2012) used the hyperlink function in concept map materials to deepen and broaden learning and to simplify the internal complexity of the material being learned, which can thus reduce intrinsic cognitive load (Chung, 2008; Musavi et al., 1995; Sweller, Merrie"nboer, \& Paas, 1998). In Figure 5, the main concept "A" and two sub-concepts " $\mathrm{B}$ " and " $\mathrm{C}$ " have relations in content, which can use the hyperlink function to broaden learning. After a student fully understands the knowledge in concept " $\mathrm{A}$ ", she/he can use the hyperlinks to acquire the knowledge of concepts " $B$ " or " $C$ ". Therefore, concepts " $B$ " and " $C$ " broaden a student's knowledge of concept " $A$ ". Furthermore, concept " $A$ " refers to sub-concept " $E$ ", and the sub-concept " $E$ " is the advanced knowledge of concept " $A$ ". When a student has understood the basic knowledge of concept " $A$ ", she/he can deepen her/his learning through the hyperlink to concept " $E$ ". Sub-concept " $E$ " is separated from concept " $A$ " in an independent webpage to simplify the page layouts and reduce the complexity involving concepts " $\mathrm{A}$ " and " $\mathrm{E}$ ". This learning can enable students to absorb and understand the learning content at their own pace. See details in Huang et al. (2012). 


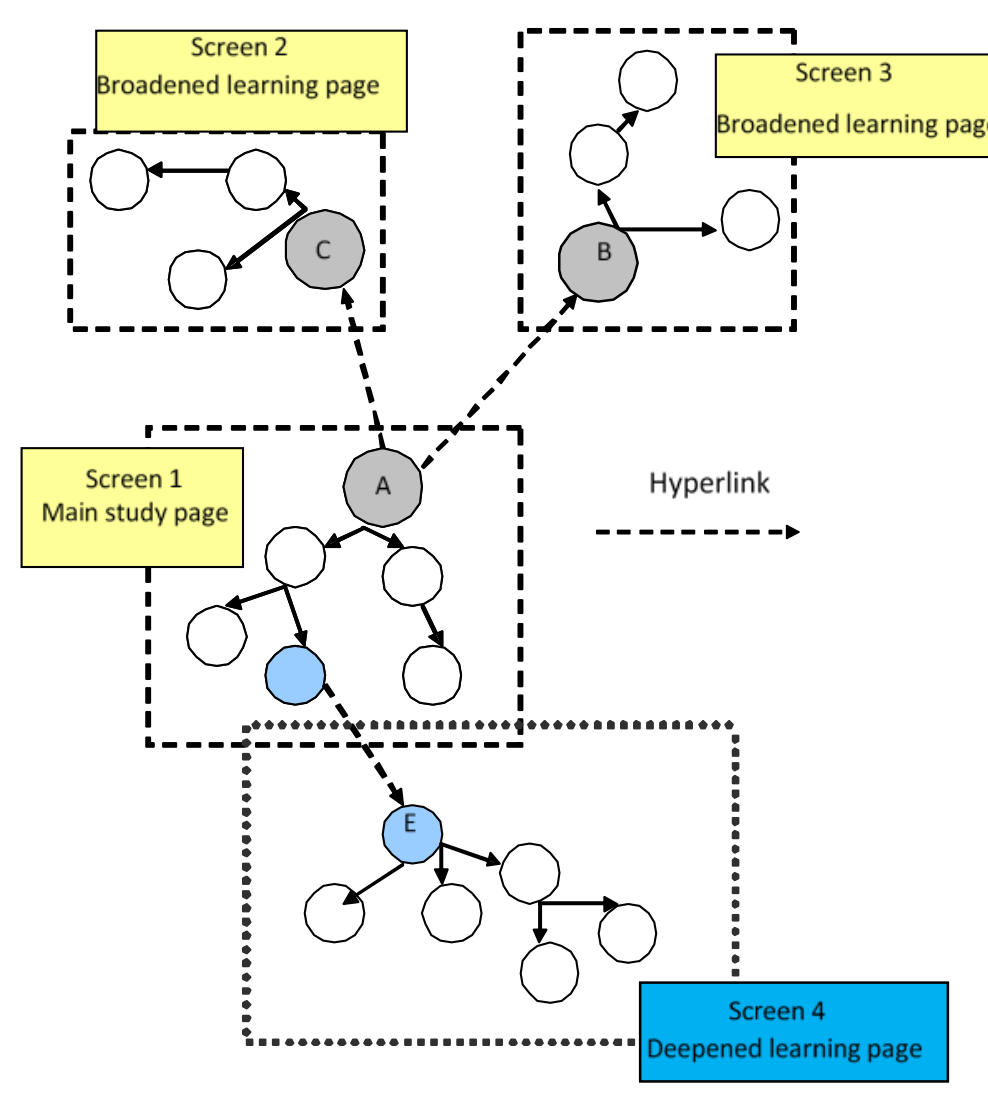

Figure 5. Multidimensional concept maps to deepened and broadened learning (Huang et al., 2012)

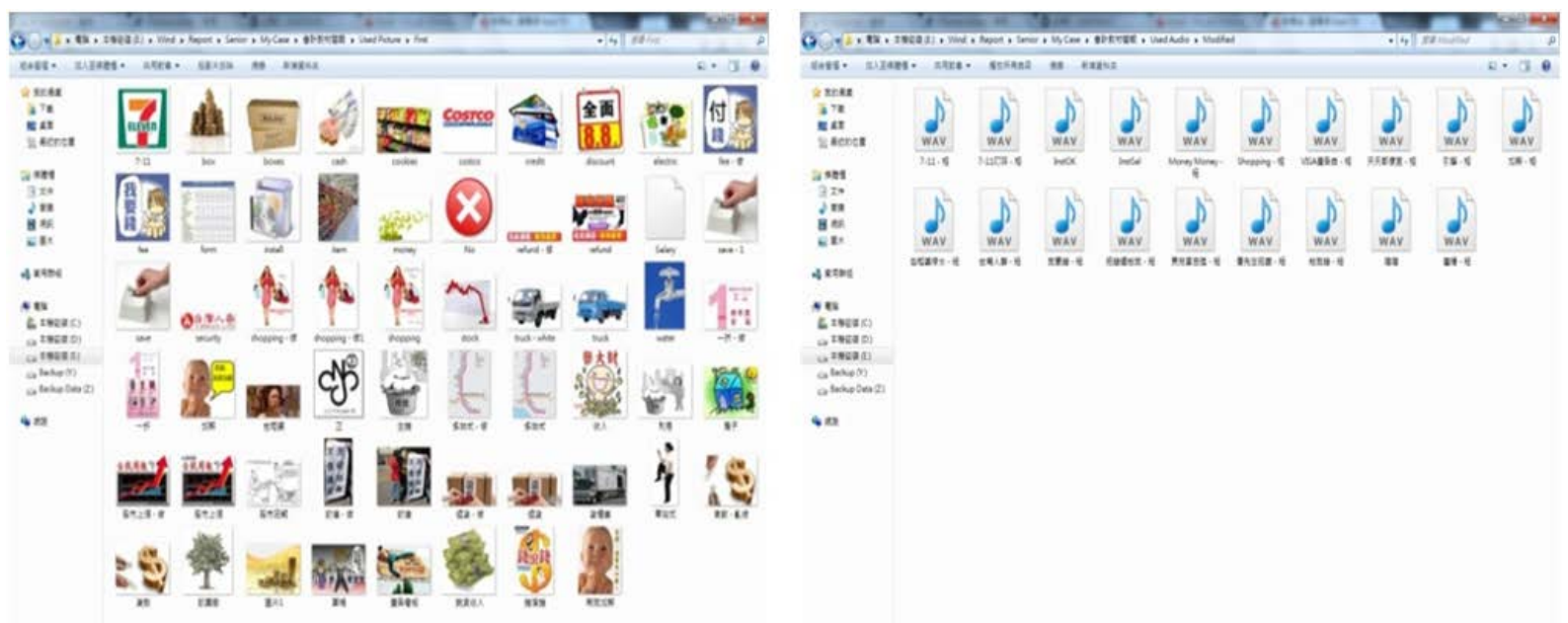

Figure 6. Image files and sound files

Following the above design standard and the studies of Plass et al. (2014), Chiou et al. (2012) and Chiou et al. (2015), the CMCMAMs consisted of 105 daily-life image files (visual system) and 45 daily-life sound files (auditory system), as shown in Figure 6. The terminology in the accounting concept maps is marked with a cubic text block. The block size is $2.65^{*} 6.8 \mathrm{~cm}$ and $3.8^{*} 6 \mathrm{~cm}$, the font size is $28 \mathrm{pt}$, and each picture is a concept map. The basic characteristics of the CMCMAMs are to attach suitable and relevant daily-life images and sounds to each accounting term and to use colours to classify the hierarchies of concept maps. Another feature of the CMCMAMs is their design for deepened and broadened learning, following Huang et al. (2012). 


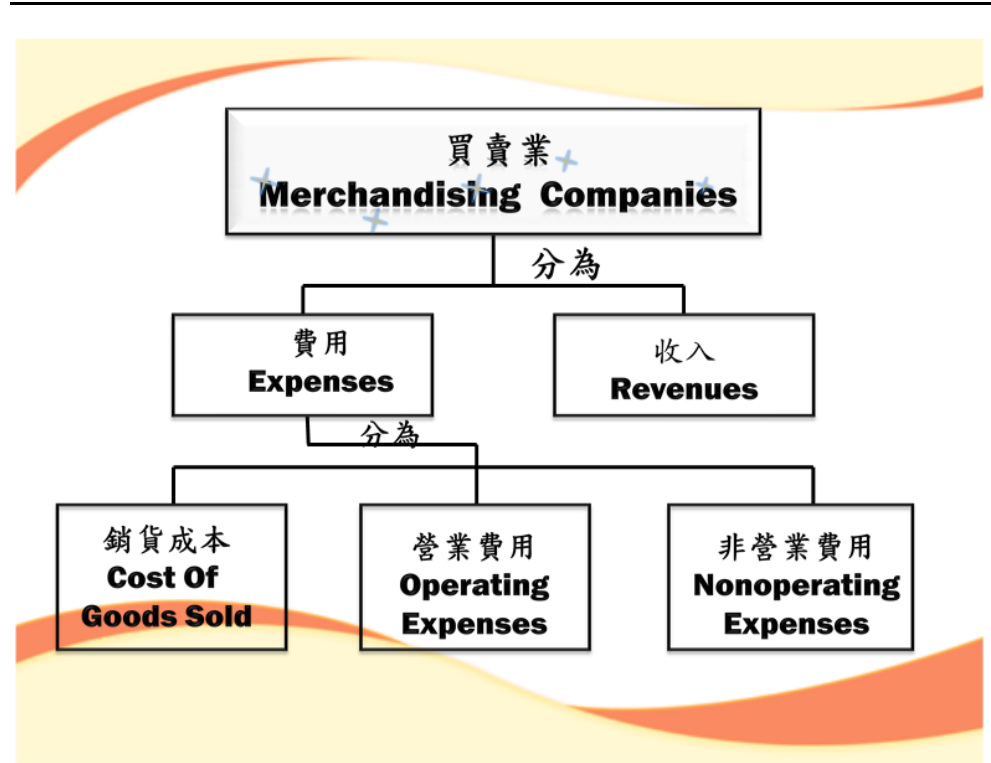

Figure 7. AMCMMs

\section{AMCMMs design}

The AMCMMs consisted only of the hyperlink function, similarly to CMCMAMs, but did not include multimedia animation, such as images or sounds (or music). They only used black and white backgrounds and achromatic colours, as shown in Figure 7.

\section{Teaching Experimental Procedure}

The study was broken down into several stages. In the preparation stage, the teacher and the researcher spent three months discussing the overall experimental processes and the experimental materials. Several tasks were completed in this stage. First, the CMCMAMs and AMCMMs were designed, and experts were asked to review them. Second, the learning achievement pre-test and post-test and the learning well-being scale were prepared. Third, a preliminary examination was implemented for the learning well-being scale and achievement pre-tests and post-tests. Fourth, the preliminary examination data were analysed. Fifth, the experimental teaching procedures were reviewed.

In the pre-test stage, the teacher spent six weeks giving two participating classes lectures with traditional linear teaching materials on journaling, posting, trial balance, and adjusting. Students were administered a learning achievement pre-test and completed the learning well-being scale in the seventh week. In the eighth week, the participating classes were individually assigned to an experimental group that used CMCMAMs and a control group that used AMCMMs. The teacher illustrated what students should pay attention to during the experimental period and explained the multimedia materials in the class.

In the formal experiment stage, the teacher spent six weeks giving two classes lectures on merchandising and inventory. Two topics, merchandising and inventory, were divided into 12 units and taught (narrated) with CMCMAMs and AMCMMs for the experimental and control classes, respectively. This was a six-week-long formal teaching experiment, and classes met $3 \mathrm{~h}$ per week. The learning achievement post-test and the learning well-being scale were administered in week fourteen.

\section{RESEARCH RESULTS}

\section{Compare Learning Achievement in the Two Groups}

\section{The homogeneous testing of regression coefficients within a group}

Homogeneity in the regression coefficients within a group indicates that the covariate coefficients (i.e., the slopes of the regression lines) are the same for each group formed by the categorical variables and measured on the dependent variable. The more this assumption is violated, likelier Type I errors are. An F test was used to test the 
Table 1. Means and standard deviations for each group on learning achievement and learning well-being

\begin{tabular}{ccccc}
\hline & \multicolumn{2}{c}{ Experimental group } & \multicolumn{2}{c}{ Control group } \\
\hline Variable & $\boldsymbol{M}$ & $\boldsymbol{S D}$ & $\mathbf{M}$ & $\mathbf{S D}$ \\
\hline Achievement & & & 58.28 & 11.79 \\
\hline Pretest & 58.75 & 12.91 & 56.38 & 19.14 \\
\hline Posttest & 70.00 & 15.52 & & 4.71 \\
\hline Well-being & & & 12.62 & 4.76 \\
\hline Prior & 13.14 & 4.59 & 12.16 & \\
\hline Posterior & 16.39 & 5.21 & & \\
\hline
\end{tabular}

Table 2. ANCOVA analysis of learning achievement for different materials

\begin{tabular}{ccccccc}
\hline Source & SS & $\boldsymbol{d f}$ & MS & $\mathbf{F}$ & $\boldsymbol{p}$ & $\boldsymbol{\eta}^{\mathbf{2}}$ \\
\hline Model & 6124.98 & 2 & 3062.49 & 10.21 & $.00^{* *}$ & 0.16 \\
\hline Constant & 27735.08 & 1 & 27735.08 & 92.45 & $.00^{* *}$ & 0.45 \\
\hline Pretest & 839.19 & 1 & 839.19 & 2.80 & .097 & 0.03 \\
\hline Groups & 5365.63 & 1 & 5365.63 & 17.89 & $.00^{* *}$ & 0.14 \\
\hline Error & 33300.46 & 111 & 300.00 & & & \\
\hline${ }^{* *} p<.01$ & & &
\end{tabular}

Table 3. A paired sample t-test of learning well-being for different materials

\begin{tabular}{cccccc}
\hline Group & Difference in Mean & $\boldsymbol{S E}$ & $\mathbf{t}$ & $\boldsymbol{p}$ & Cohen's $\boldsymbol{d}$ \\
\hline experimental & 3.25 & 0.95 & 3.43 & $.00^{*}$ & .71 \\
\hline Control & -0.47 & 0.83 & 0.56 & .58 & -.10 \\
\hline${ }^{* *} p<.01$ & & & &
\end{tabular}

assumption of homogenous regression coefficients within a group, and the results were insignificant, $\mathrm{F}(1,110)=$ $2.94, p=.09$, indicating that the ANCOVA analysis could be continued.

\section{The one-way ANCOVA analysis}

The mean score on the learning achievement post-test for the experimental group was 70, and the standard deviation was 15.52 . The mean score on the learning achievement post-test for the control group was 56.38 , and the standard deviation was 19.14, as shown in Table 1. The difference in the scores between the two groups (13.62) was significant, $\mathrm{F}(1,111)=17.89, p<.01, \eta^{2}=0.14$, see Table 2 . Therefore, after excluding the effect of pre-test scores for academic achievement, students in the experimental group performed significantly better than those in the control group. Therefore, H1 was supported by the empirical data.

\section{Comparing Learning Well-being in the Two Groups}

Learning well-being scales with the same questions before and after the learning phase were used to measure the effect of learning with CMCMAMs and AMCMMs on students' learning well-being. A paired sample t-test was used to analyze the results. The mean score on learning well-being in the experimental group before the learning phase was 13.14, and the standard deviation was 4.59. The mean score on learning well-being in the experimental group after the learning phase was 16.39 , and the standard deviation was 5.21 . The difference in the scores on learning well-being before and after the learning phase was $3.25, \mathrm{t}(55)=3.43, p<.01$, indicating that students' learning well-being significantly increased when they learned with CMCMAMs in contrast to when they learned with traditional linear teaching materials. The effect size (Cohen's $d=.71$ ) on learning well-being was medium to large for CMCMAMs.

The mean score on learning well-being in the control group before the learning phase was 12.62, and the standard deviation was 4.71 . The mean score on learning well-being in the control group after the learning phase was 12.16, and the standard deviation was 4.76 . The difference in the scores on learning well-being before and after the learning phase was $-0.46, \mathrm{t}(57)=0.56, p=.58$, indicating that students' learning well-being was not higher when they learned with AMCMMs than when they learned with traditional linear teaching materials. The effect size (Cohen's $d=-.01$ ) showed no effect on learning well-being for AMCMMs. Therefore, H2 was supported by the empirical data. 


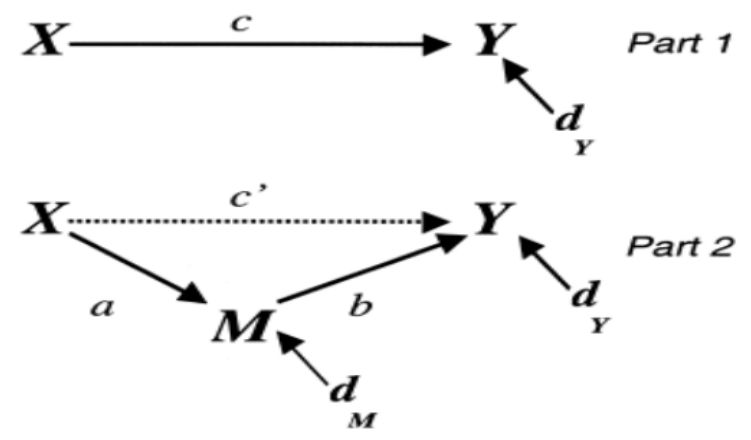

Data source: Shrout, P. \& Bolger, E. (2002). Mediation in experimental and non-experimental studies: New procedures and recommendations, Psychological Methods, 7(4), 422-445.

Figure 8. Mediating effect

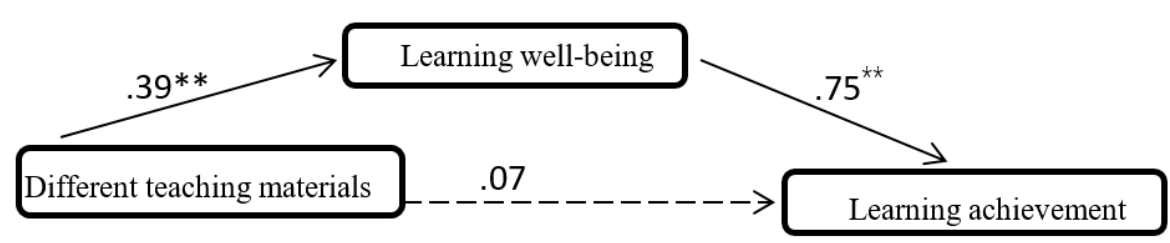

** $p<.01$

Figure 9. Learning well-being mediates the effect of learning with different teaching materials on students' learning achievement

\section{Learning Well-being Mediating the Influence of Learning with Different Materials on Students' Learning Achievement}

\section{The mediating effect}

To investigate mediating effects, Shrout and Bolger (2002) and Sobel (1982) suggested the following regressions:

$$
Y=\beta_{0}+c X+\mu, M=\alpha_{0}+a X+\varepsilon, Y=\beta_{0}+c^{\prime} X+b M
$$

A result $=c-c^{\prime}=a^{*} b$ reflects a mediating effect if it is significantly greater than 0 . In Figure 8, Part 1 is a traditional regression, where $\mathrm{Y}$ is the dependent variable and $\mathrm{X}$ is the independent variable. If regression coefficient $\mathrm{c}$ is significant, it means that $X$ has a total effect on $Y$. Part 2 is a mediating regression, where $M$ may mediate the relationship between $X$ and $Y$. If $c^{\prime}$ is significantly less than $c$, it indicates that this regression has a mediating effect. If $c^{\prime}$ is not statistically significant, it indicates that this regression has a mediating (indirect) effect but not a direct effect. That is, M has a full mediating effect on the relationship between X and Y (Shrout \& Bolger, 2002).

In Figure 9, the effect of different teaching materials on learning well-being was significant, (coefficient beta $=$ $.39, p<.01$ ), and the effect of learning well-being on learning achievement was significant (coefficient beta $=.75, p$ $<.01$ ); however, the relationship between different teaching materials and learning achievement did not reach statistical significance (coefficient beta $=.07, p>.05$ ). The results showed that learning well-being fully mediated the effect of learning with different multimedia materials on students' learning achievement.

\section{Testing path coefficient}

Regression analysis methods can explore whether the total effect of a path coefficient is significant, but a mediating path coefficient test was not possible. A Sobel (1982) test was performed to test the mediating effect. The Sobel test formula is

$$
z=\frac{a \times b}{\sqrt{\sigma_{a}^{2} \times b^{2}+\sigma_{b}^{2} \times a^{2}}}
$$

$\sigma_{a}^{2}$ and $\sigma_{b}^{2}$ are the variances of regression coefficients a and $\mathrm{b}$ in equation 1 . At $\alpha=0.05$, the $\mathrm{z}$ value $>1.96$, indicating the mediating effect is significant (Sobel, 1982).

According to formula (2), the path coefficients are $a=4.24$ (different materials and learning well-being) and $b=2.6$ (learning well-being and learning achievement), 


$$
Z=\frac{(4.24) x(2.6)}{\sqrt{(4.24)^{2} x(0.22)^{2}+(2.6)^{2} x(0.93)^{2}}}=4.25>1.96
$$

The results indicated that the learning well-being mediated the influence of learning with different multimedia materials on students' learning achievement.

A sample size smaller than 400 may result in skewness (Stone \& Sobel, 1990). To address this problem, a bootstrapped method was used to up the sample size to 1,000. The Sobel test was also significant:

$$
Z=\frac{(4.24) x(2.6)}{\sqrt{(4.24)^{2} x(0.21)^{2}+(2.6)^{2} x(0.94)^{2}}}=4.24>1.96
$$

Therefore, learning well-being mediated the relationship between learning with different multimedia materials and learning achievement. H3 was supported by the empirical data.

\section{DISCUSSIONS AND CONCLUSIONS}

The purpose of this research was to examine the efficacy of the emotional design of multimedia materials to facilitate learning. The empirical results showed that learning with CMCMAMs can enhance academic achievement. The result is consistent with Chiou et al. (2015) and Tien et al. (2018) which empirically showed that teaching materials combining multimedia animation and multidimensional concept maps improve learning achievement and memory retention. The results also showed that students' learning well-being-specifically, academic achievement - was raised when the teacher used CMCMAMs to teach.

The CMCMAMs have some better characteristics than AMCMMs. First, multimedia animation includes dailylife images, fashion, advertising and pop music with which students are familiar. Second, multidimensional concept maps use hierarchical warm colours. Multimedia animation can contribute a positive cognitive outcome with multidimensional concept map materials, which supports Mayer's (2005) Cognitive Theory of Multimedia Learning. Mayer $(2001,2005)$ showed that students learn better with textual and pictorial representations than with only textual information. According to the multimedia principle (Mayer, 2001; Mayer \& Moreno, 2002), textual and pictorial representations (concept maps and animation) can organize verbal and visual mental models, build connections, between them, systematically integrate them with prior knowledge and store them in the long-term memory. Dual Coding Theory (Paivio, 1986) can explain the positive effect of learning with multimedia materials that combine animation with multidimensional concept maps on cognitive achievement based on its incorporation of verbal (i.e., concept maps, narration and sounds) and visual (i.e., animation) information, which is better than verbal (i.e., concept maps and narration) materials alone. Concept maps, a verbal representation with an integrated structure and systematic attributes, can improve learning performance by helping students build knowledge frameworks and understand complex connections among major and minor concepts (Chiou et al., 2015). Concept maps are also useful as an instructional technology to facilitate meaningful learning (Chiou, 2009; Novak, 1990), which is the goal of multimedia learning (Mayer \& Moreno, 2003). However, text (words) and maps, only within the verbal system, can cause information and cognitive overload while ignoring the visual system (Paivio, 1971).

According to Tversky, Morrison, and Betrancourt (2002) and Moreno and Ortegano-Layne (2008), animated images that convey certain visual information and display characteristics of an event in a context can be incorporated with verbal information (i.e., concept maps) to reduce students' learning burden and hence improve their learning achievement. Two methods were used to enhance the effectiveness of animation in the present study: First, daily-life animation with which students were familiar, such as 7-11 or a water tape, which was learning goalrelevant information, was used to reduce cognitive load (Park et al., 2015). Second, interesting and appealing animation, including daily-life images, fashion, advertisements and pop music incorporated with colourful multidimensional concept maps, was used to attract students' attention and induce positive emotions (Chiou et al., 2015; Plass et al., 2014; Tien et al., 2018; Um et al., 2012).

Furthermore, hierarchical, warm, colourful multidimensional concept maps have some advantages in enhancing learning well-being and enhancing learning achievement. First, hierarchical multidimensional concept maps are helpful for reducing cognitive load and enhancing learning achievement. Second, the use of warm colours and concept maps is conducive to inducing positive emotions and learning well-being. Multidimensional concept maps adequately use the segmenting, pretraining and signalling principle and the integrated presentation suggested by Mayer and Moreno (2003) to reduce cognitive load in multimedia learning. The structures of multidimensional concept maps follow the segmenting principle and the limited capacity of working memory and use hyperlink technology to structure complicated concepts into several individual but relevant concepts in order to simplify the computer display (Huang et al., 2012). Multidimensional concept maps, including concepts (building component models), propositions and hierarchies (building casual models), also conform to the pertaining principle. Furthermore, concept maps, selecting key and important words (i.e., concepts) that students need to learn in their learning task to eliminate redundancy, also adhere to the signalling principle and the non- 
redundant presentation. Finally, concept maps are built based on the theory of meaningful learning, which integrates new knowledge into existing networks of concepts and propositions (Malone \& Dekkers, 1984) and place the text within maps, so concept maps are integrated presentations. Based on these advantages, empirical studies (Huang et al., 2012; Chiou et al., 2015; Tien et al., 2018) have indicated that multidimensional concept maps are better at reducing cognitive load and improving learning achievement than on-screen linear text.

However, this study compared the incorporation of animation into multidimensional concept maps with multidimensional concept maps. As Mayer and Moreno (2003) and Park et al. (2015) stated, adding animation to multimedia materials did not conform with the coherence principle and imposed extraneous cognitive load on learners. We predicted that daily-life animation with learning-goal-relevant information could overcome the extraneous cognitive load; however, we did not empirically prove its effectiveness in this paper. Therefore, we cannot draw conclusions regarding the contribution of incorporating animation into multidimensional concept maps on reducing cognitive load, although we verified that incorporating animation into multidimensional concept maps had a positive effect on students' learning achievement. How can materials help improve academic achievement? The findings of this study indicated that learning well-being mediated the effect of learning with multimedia materials that contained animation and multidimensional concept maps on their learning achievement. The findings supported Moreno's (2006) Cognitive-Affective Theory of Learning with Media and the effectiveness of positive emotions on learning (Um et al., 2012; Plass et al., 2014). Daily-life animation with interesting and appealing real-life images and sounds can induce positive emotions in learners (Um et al., 2012; Plass et al., 2014) and increase their learning well-being. Additionally, we used warm colours in concept maps (see Figures 2-4), which were similar to Plass et al.'s (2014) warm colours, in conjunction with round shapes. We found they could induce positive emotions and increase learning well-being. Empirical studies by Chiou et al. (2012) and Chiou et al. (2015) showed that students felt satisfied with and interested in colourful concept maps. Thus, based on our results, we can deduce that learning with multimedia materials that contained daily-life animation and multidimensional concept maps improved students' learning well-being. The results of the Sobel (1982) test indicated that learning with multimedia materials that incorporated animation and hierarchical colourful multidimensional concept maps indirectly but not directly influenced learning achievement through learning well-being.

Based on the empirically positive results of animation and multidimensional concept maps, in comparison to traditional concept maps and traditional materials by Hunag et al. (2012), Chiou et al. (2015), and Tien et al. (2018), this paper further verified the emotional and cognitive effectiveness of daily-life multimedia animation and colours in multidimensional concept maps. The results offer theoretical and practical implications. First, concept maps can promote meaningful learning, which is the goal of multimedia learning, as stated by Mayer and Moreno (2003). Our study found that multimedia designers aiming to enhance learners' learning well-being and learning achievement can use animation combined with hierarchical colourful multidimensional concept maps rather than traditional concept maps or linear on-screen text. Second, this research contributes to the empirical evidence supporting Paivio's (1986) Dual Coding Theory, Mayer's (2005) Cognitive Theory of Multimedia Learning and Moreno's (2006) Cognitive-Affective Theory of Learning with Media. Our results showed that learning well-being mediates multimedia materials and cognitive achievement. Therefore, affective function such as learning well-being is an important factor that needs to be considered in addition to cognitive factors when learners learn from multimedia materials, which is consistent with Plass et al. (2014). More importantly, differing from Um et al. (2012), Plass et al. (2014), and Park et al. (2015), this research combines animation with concept maps rather than with text to design multimedia learning materials. This is a fresh perspective of the affective and cognitive effects of multimedia materials and the optimal design of multimedia materials. Finally, together with the results of the present and previous studies (Huang et al., 2012; Chiou et al., 2012; Chiou et al., 2015; Tien et al., 2018) research on combining animation with colourful multidimensional concept maps in multimedia learning provides guidelines and suggestions for the design of learning environments in the present digital age.

\section{REFERENCES}

Anderson, J. R. \& Bower, G. H. (1973). Human associative memory. Washington, DC: Winston.

Ausubel, D. P. (1963). The psychology of meaningful verbal learning. New York: Grune \& Stratton.

Baddeley, A. D. (1992). Working memory. Science, 255, 556-559. https:// doi.org/10.1126/science.1736359

Beyerbach, B. A. (1998). Development a technical vocabulary: preserves teachers' concept maps. Teaching and Teacher Education, 4, 339-347. https:/ / doi.org/10.1016/0742-051X(88)90032-7

Biehler, R. F., \& Snowman, J. (1990). Psychology applied to teaching (6 $6^{\text {th }}$ ed.). Boston, MA: Houghton Mifflin.

Bieneik, V. Y. (2008). Implementation of a cognitive apprenticeship model on student programming and perception of problem-solving ability: An exploratory study. A dissertation of Ph.D., Capella University. 
Brookover, W. B., Beady, C., Flood, P., Schweitzer, J., \& Wisenbaker, J. (1979). School social systems and student achievement: School can make a difference. New York: Praeger.

Chiou, C. C. (2008). The effect of concept mapping on students' learning achievements and interests. Innovations in Education and Teaching International, 45, 375-387. https:/ / doi.org/10.1080/14703290802377240

Chiou, C. C. (2009). Effects of concept mapping strategy on learning performance in business and economics statistics. Teaching in Higher Education, 14, 55-69. https:/ / doi.org/10.1080/13562510802602582

Chiou, C. C., Lee, L. T., \& Liu, Y. Q. (2012). Effect of Novak colorful concept map with digital teaching materials on student academic achievement. Procedia - Social and Behavioral Sciences, 64, $192-201$. https://doi.org/10.1016/j.sbspro.2012.11.023

Chiou, C. C., Tien, L. C., \& Lee, L. T. (2015). Effects on learning of multimedia animation combined with multidimensional concept maps. Computers $\mathcal{E}$ Education, 80, 211-223. https:/ / doi.org/10.1016/j.compedu.2014.09.002

Chung, K. K. H. (2008) What effect do mixed sensory mode instructional formats have on both novice and experienced learners of Chinese characters? Learning and Instruction, 18, 96-108. https:// doi.org/10.1016/j.learninstruc.2007.01.001

Deimann, M., \& Keller. J. M. (2006). Volitional aspects of multimedia learning. Journal of Educational Multimedia and Hypermedia, 15, 137-158.

Ebel, R. L. \& Frisbie, D. A. (1991). Essentials of educational measurement (5 ${ }^{\text {th }}$ ed.). Englewood Cliffs, NJ: Prentice-Hall.

Efklides, A., Kourkoulou, A., Mitsiou, F., \& Ziliaskopoulou, D. (2006). Metacognitive knowledge of effort, personality factors, and mood state: Their relationships with effort-related metacognitive experiences. Metacognition and Learning, 1, 33-49. https:/ / doi.org/10.1007/s11409-006-6581-0

Fiorella, L., \& Mayer, R. E. (2015). Learning as a generative activity: Eight learning strategies that promote understanding. New York: Cambridge University Press. https:/ / doi.org/10.1017/CBO9781107707085

Fredrickson, B. L. (1998). What good are positive emotions? Review of General Psychology, 2, 300-319. https://doi.org/10.1037/1089-2680.2.3.300

Garner, R., Gillingham, M., \& White, C. (1989). Effects of "seductive details" on macroprocessing and microprocessing in adults and children. Cognition and Instruction, 6, 41-57. https:/ / doi.org/10.1207/s1532690xci0601_2

Harp, S. F., \& Mayer, R. E. (1998). The role of interest in learning from scientific text and illustrations: On the distinction between emotional and cognitive interest. Journal of Educational Psychology, 89, 92-102. https:/ / doi.org/10.1037/0022-0663.89.1.92

Heidig, S., Müller, J., \& Reichelt, M. (2015). Emotional design in multimedia learning: Differentiation on relevant design features and their effects on emotions and learning. Computers in Human Behavior, 44, 81-95. https://doi.org/10.1016/j.chb.2014.11.009

Holzinger, A., Kickmeier-Rust, M. \& Albert, D. (2008). Dynamic media in computer science education; Content complexity and learning performance: Is less more? Educational Technology \& Society, 11, 279-290.

Huang, H. S., Chiou, C. C., Chiang, H. K., Lai, S. H., Huang, C. Y., \& Chou, Y. W. (2012). Effects of multidimensional concept maps on fourth graders' learning in web-based computer course. Computers \& Education, 58, 863873. https:// doi.org/10.1016/j.compedu.2011.10.016

Isen, A. M., Daubman, K. A., \& Nowicki, G. P. (1987). Positive affect facilitates creative problem solving. Journal of Personality and Social Psychology, 52, 1122-1131. https:// doi.org/10.1037/0022-3514.52.6.1122

Isen, A. M., Shalker, T. E., Clark, M., \& Karp, L. (1978). Affect, accessibility of material in memory, and behavior: A cognitive loop? Journal of Personality and Social Psychology, 36, 1-12. https://doi.org/10.1037/00223514.36.1.1

Keefe, J. W., \& Jenkins, J. M. (1997). Instruction and the learning environment. NY: Eye On Education, Inc.

Kerlinger, F. N. (1986). Foundations of behavioral research. New York: Holt, Rinehart and Winston.

Kieso, D., Weygandt, J., \& Kimmel, P. (2012). Financial Accounting (8th ed). John Wiley \& Sons.

Lamberski, R. J. (1980). A comprehensive and critical review of the methodology and findings in color investigations. Syracuse, NY: ERIC.

Lehman, S., Schraw, G., McCrudden, M. T., \& Hartley, K. (2007). Processing and recall of seductive details in scientific text. Contemporary Educational Psychology, 32, 569-587. https://doi.org/10.1016/j.cedpsych.2006. 07.002 
Lu, L., \& Lin, Y. C. (2003). Academic achievement and self-concept: Chinese and Japanese adolescents. Fu Jen Studies: Science and Engineering, 37, 43-62.

Lyubomirsky, S., King, L. A., \& Diener, E. (2005). The benefits of frequent positive affect: Does happiness lead to success? Psychological Bulletin, 131, 803-855. https:/ / doi.org/10.1037/0033-2909.131.6.803

Mayer, R. E. \& Moreno, R. (2003).Nine ways to reduce cognitive load in multimedia learning. Education psychologist, 38, 43-52. https://doi.org/10.1207/S15326985EP3801_6

Mayer, R. E. (1997). Multimedia learning: Are we asking the right questions. Educational Psychologist, 32, 1-19. https://doi.org/10.1207/s15326985ep3201_1

Mayer, R. E. (2003). The promise of multimedia learning: Using the same instructional design methods across different media. Learning and Instruction, 13, 125-139. https:/ / doi.org/10.1016/S0959-4752(02)00016-6

Mayer, R. E. (2005). Cognitive theory of multimedia learning. New York, NY: Cambridge University Press. https://doi.org/10.1017/CBO9780511816819.004

Mayer, R. E. (2009). Multimedia learning (2nd ed.). New York: Cambridge University Press. https:/ / doi.org/10.1017/CBO9780511811678

Mayer, R. E. (2014). Computer games for learning: An evidence-based approach. Cambridge, MA: MIT Press.

Mayer, R. E., \& Moreno, R. (2002).Animation as an aid to multimedia learning. Educational Psychology Review, 14, 87 -99. https://doi.org/10.1023/A:1013184611077

Mayer, R. E., Heiser, H., \& Lonn, S. (2001). Cognitive constraints on multimedia learning: When presenting more material results in less understanding. Journal of Educational Psychology, 93, 187-198. https:/ / doi.org/10.1037/0022-0663.93.1.187

McPherson, S. (2000). Expert-novice differences in planning strategies during collegiate singles tennis competition. Journal of Sport and Exercise Psychology, 22, 39-62. https:/ / doi.org/10.1123/jsep.22.1.39

Miller, G. A. (1956). The magical number seven, plus or minus two: Some limits on our capacity for processing information. Psychological Review, 63, 81-97. https://doi.org/10.1037/h0043158

Moreno, R. (2006). Does the modality principle hold for different media? A Test of the method-affects-learning hypothesis. Journal of Computer Assisted Learning, 22, 149-158. https://doi.org/10.1111/j.13652729.2006.00170.x

Novak, J. D. (1990). Concept mapping: A useful tool for science education. Journal of Research in Science Teaching, 27, 937-950. https:/ / doi.org/10.1002/tea.3660271003

Novak, J. D., \& Gowin, D. B. (1984).Learning how to learn. New York: Cambridge University Press. https:/ / doi.org/10.1017/CBO9781139173469

Paivio, A. (1986). Mental representation: A dual coding approach. Oxford, England: Oxford University Press.

Paivio,A., Sadoski, M. (2011). Lexicons, contexts, events, and images: Commentary on from the perspective of dual coding theory. Cognitive Science, 35, 198-209. https:/ / doi.org/10.1111/j.1551-6709.2010.01146.x

Park, B., \& Brünken, R. (2015). The Rhythm method: A new method for measuring cognitive load - an experimental dual-task study. Applied Cognitive Psychology, 29, 232-243. https:/ / doi.org/10.1002/acp.3100

Park, B., Flowerday, T., \& Brünken, R. (2015). Cognitive and affective effects of seductive details in multimedia learning. Computers in Human Behavior, 44, 267-278. https:/ / doi.org/10.1016/j.chb.2014.10.061

Park, B., Korbach, A., \& Brünken, R. (2015). Do learner characteristics moderate the seductive-details-effect? A cognitive load-study using eye-tracking. Educational Technology \& Society, 18, 24-36.

Park, B., Plass, J. L., \& Brünken, R. (2014). Cognitive and affective processes in multimedia learning. Learning and Instruction, 29, 125-127. https:/ / doi.org/10.1016/j.learninstruc.2013.05.005

Pekrun, R. (2006). The control-value theory of achievement emotions: Assumptions, corollaries, and implications for educational research and practice. Educational Psychology Review, 18, 315-341. https:/ / doi.org/10.1007/s10648-006-9029-9

Pekrun, R., Goetz, T., Titz, W., \& Perry, R. P. (2002). Academic emotions in students' self-regulated learning and achievement: A program of quantitative and qualitative research. Educational Psychologist, 37, 91-106. https://doi.org/10.1207/S15326985EP3702_4

Pekrun, R., Götz, T., Frenzel, A. C., Barchfeld, P., \& Perry, R. P. (2011). Measuring emotions in students' learning and performance: The achievement emotions questionnaire (AEQ). Contemporary Educational Psychology, 36, 36-48. https:/ / doi.org/10.1016/j.cedpsych.2010.10.002

Pett, D. \& Wilson, T. (1996). Color research and its application to the design of instructional materials. ETR E D, 44, 19-35. https:// doi.org/10.1007/BF02300423 
Plass, J. L., Heidig, S., Hayward, E. O., Homer, B. D., \& Um, E. (2014). Emotional design in multimedia learning: Effects of shape and color on affect and learning. Learning and Instruction, 29, 128-140. https:// doi.org/10.1016/j.learninstruc.2013.02.006

Plass, J., Moreno, R., \& Brünken, R. (Eds.) (2010). Cognitive load theory. New York, NY: Cambridge University Press. https://doi.org/10.1017/CBO9780511844744

Sadoski, M. (2005). A dual coding view of vocabulary learning. Reading $\mathcal{E}$ Writing Quarterly, 21, 221-238. https://doi.org/10.1080/10573560590949359

Schar, S. G., \& Zimmermann, P. G. (2007). Investigating means to reduce cognitive load from animations: applying differentiated measures of knowledge representation. Journal of Research on Technology in Education, 40, 6478. https:/ / doi.org/10.1080/15391523.2007.10782497

Shrout, P. E., \& Bolger, N. (2002). Mediation in experimental and nonexperimental studies: New procedures and recommendations. Psychological Methods, 7, 422-445. https://doi.org/10.1037/1082-989X.7.4.422

Sobel, M. E. (1982). Asymptotic confidence intervals for indirect effects in structural equation model. In S. Leinhardt (Ed.) Sociological methodology. San Francisco: Jossey-Bass. https:// doi.org/10.2307/270723

Stone, C. A., \& Sobel, M. E. (1990). The robustness of estimates of total indirect effects in covariance structure models estimated by maximum likelihood. Psychometrika, 55, 337-352. https://doi.org/10.1007/BF02295291

Sweller, J. (1988). Cognitive load during problem solving: Effects on learning. Cognitive Science. 12, 257-285. https:/ / doi.org/10.1207/s15516709cog1202_4

Sweller, J., van Merrie“nboer, J., \& Paas, F. (1998). Cognitive architecture and instructional design. Educational Psychology Review, 10, 251-296. https:/ / doi.org/10.1023/A:1022193728205

Tien, L. C., Chiou, C. C., \& Liao, C. W. (2018). Effect of digital materials with combining multimedia and concept maps on cognitive learning: A mediating effect of cognitive load. International Journal on Digital Learning Technology, 10(1), 95-126. https:// doi.org/10.3966/2071260X2018011001004

Um, E., Plass, J. L., Hayward, E. O., \& Homer, B. D. (2012). Emotional design in multimedia learning. Journal of Educational Psychology, 104, 485-498. https:/ / doi.org/10.1037/a0026609

Woolfolk, A. (2007). Educational psychology (10 th ed.). Boston, MA: Allyn \& Bacon.

\section{http://www.ejmste.com}

